\title{
The antihyperlipidemic drug Potassium Piperate impairs migration and tumorgenesis of breast cancer cells via upregulation of miR-31
}

Junping Lu

Inner Mongolia University

Xiaoxia Tian

Inner Mongolia University

Mailisu Mailisu

Inner Mongolia University

Morigen Morigen

Inner Mongolia University

Lifei Fan ( $\square$ lifei.fan@imu.edu.cn )

Inner Mongolia University

\section{Research Article}

Keywords: Potassium Piperate, miR-31, Breast cancer, Cell migration, Drug combination

Posted Date: March 19th, 2021

DOI: https://doi.org/10.21203/rs.3.rs-290044/v1

License: (c) (i) This work is licensed under a Creative Commons Attribution 4.0 International License. Read Full License 


\section{Abstract}

Background Breast cancer is a leading malignant tumor which causes deaths among women, and metastasis is the primary cause for mortality in breast cancer. Due to the involvement of many regulatory molecules and signaling pathways, the occurrence and development process of metastasis needs to be further studied. MicroRNAs (miRNAs) are ubiquitously expressed small non-coding RNAs that have been shown to play an important role in the diagnosis and treatment of many diseases, as well as constituting an attractive candidate to control metastasis. In this study, we tried to uncover the mechanism of GBK in impairing breast cancer cell invasion and metastasis.

Methods We treated cancer cells with GBK or not, found its target miRNA by analyzed miRNA transcriptional changes and the miRNA target genes by performed with the QT-PCR and Western Blot. The proliferation of breast cancer cells in vitro and in vivo under combination treatment with GBK and DDP was measured by CCK-8 kit and the nude mice tumor formation experiment.

Results We found tumor suppressor miR-31 was a main target of GBK. GBK treatment affected the epigenetic modification at $\mathrm{CpG}$ sites by downregulating DNA methyltransferases, thus the methylation levels at CpG of IncRNA LOC554202 decreased significantly, and in turn upregulating of both miR-31 and its host gene LOC554202 in breast cancer cells. We also observed significant inhibition of miR-31 target genes under GBK stimulation, including RhOA, WAVE3 and SATB2, which all closely related to cancer cell invasion, migration and proliferation. Furthermore, we revealed that combination treatment with GBK and DDP had synergistic and dose reduction potential in inhibiting the proliferation of breast cancer cells in vitro and in vivo, especially in TNBC.

Conclusion This study further analyzes the target and underlying mechanism of GBK in inhibiting breast cancer migration and invasion, and provides theoretical support for the development of GBK as an auxiliary drug for clinical treatment.

\section{Introduction}

Breast cancer is now the most frequently diagnosed cancer and the second leading cause of cancerrelated death in women worldwide. Strategies targeting the primary tumour have markedly improved, including surgery, chemotherapy, radiation therapy, hormone therapy and targeted therapy, but metastasis remains the greatest clinical challenge in breast cancer. The understanding of its mechanisms needs to be further investigated in order to improve the long-term control of breast cancer progression. Previous research has shown that the deregulated expression of micro RNAs (miRNAs) was intimately associated with breast tumor invasion and metastasis [1].

In recent years, miRNAs are of great importance in the research of gene expression regulation. Ubiquitously expressed miRNAs are approximately 19 to 24 nucleotides in length. miRNAs functions through binding to the complementary sequences of their target mRNAs, leading to mRNA degradation as well as downregulation or suppression of protein synthesis subsequently. miRNAs play a pivotal role in 
various cellular processes in vivo, such as proliferation, migration, cell death, and cell cycle regulation[2]. The expression pattern of miRNA is different among different subtypes of breast cancer, such as let-7c, miR-10a and let-7f are related with luminal type A breast cancer; miR-18a, miR-135b, miR-93 and miR-155 have been shown to be related to basal cell subtype; while miR-142-3p and miR-150 have been shown to be related to HER2-positive subtype[3]; miR-10b, miR-26a and miR-153 have been used as potential biomarkers for Triple Negative Breast Cancer (TNBC)[4]. About 70\% of breast cancers are estrogen receptor (ER) positive or progesterone receptor $(\mathrm{PgR})$ positive. ER controls the expression of multiple genes and proteins through genomic and non-genomic pathways, whereas $\mathrm{PgR}$ is induced by $\mathrm{ER}$, and PgR-related signal transduction pathways are closely related to the occurrence and development of breast cancer [3]. The tumor suppressor miRNAs that have been identified in breast cancer including miR206, miR-17-5p, miR-125a, miR-125b, miR-200, let-7, miR-34, and miR-31. On contrary, the expression of miR-21, miR-155, miR-10b, miR-373 and miR-520c is positively correlated with the occurrence of breast cancer[5].

Piper longum L. is a traditional anti-hyperlipidemic drug in China, which fruit contains piperine, piperlonguminine and pipernonaline. Potassium piperonate (GBK) is a derivative of piperine. GBK has the functions of reducing blood lipid and cholesterol, which is comparable to that of the commercial antihyperlipidemic drug statins [6]. In addition, previous studies have shown that GBK has a certain antitumor effect, especially in breast cancer. GBK can specifically inhibit the viability of a variety of breast cancer cells by arresting the cell cycle at the G1 phase and inhibiting cell proliferation. Furthermore, GBK could induce breast cancer cell apoptosis through mitochondrial-dependent pathway. However, whether GBK could inhibit breast cancer cell invasion and metastasis has not been investigated yet.

In this study, we tried to uncover the mechanism of GBK in impairing breast cancer cell invasion and metastasis, and aimed to identify the main target of GBK by analyzing miRNA expression patter changes under GBK treatment. Furthermore, we explored whether there are better outcomes in inhibiting the growth and migration of breast cancer cells when chemotherapy drug is combined with GBK in vitro and in vivo. This study further analyzed the target and underlying mechanism of GBK in inhibiting breast cancer, and provide theoretical support for the development of GBK as an auxiliary drug for clinical treatment.

\section{Results}

\section{GBK impairs migration and invasion of breast cancer cells}

In order to investigate the effect of GBK on the migration and invasion of breast cancer cells, would healing and transwell cell invasion assays were performed. The triple negative breast cancer cells SUM159, ER-positive breast cancer cells MCF-7 and normal human epithelial mammary cell line MCF-10A were scratched and photographed, and different concentrations of GBK were applied. After 24 hours of culture, cell images were captured, and the cell motility changes were analyzed. In order to rule out the influence of cell proliferation, we switched to $1 \%$ low serum medium after the scratch treatment and took pictures within one cell cycle. 
The results showed that the wound closure ability of both SUM-159 and MCF-7 cells was significantly inhibited by GBK. The inhibition rate of cell migration is $59 \%$ in $150 \mu \mathrm{g} / \mathrm{mL}\left(\mathrm{IC}_{50}\right.$ of SUM-159)

concentration of GBK treatment group, and further increased to $71 \%$ in the $300 \mu \mathrm{g} / \mathrm{mL}$ treatment group (Fig. 1A and B). Moreover, in SUM-159 cells GBK treatment inhibited invasion in transwell invasion assay by $64 \%$ in the $150 \mu \mathrm{g} / \mathrm{mL}$ concentration and $92 \%$ in the $300 \mu \mathrm{g} / \mathrm{mL}$ concentration, respectively (Fig. 1C and D). In contrast, apply of GBK in MCF-7 human non-invasive breast cancer cells also impaired cell invasion, but in a less obvious level (Fig. $1 \mathrm{C}$ and D). Taken together, these data suggest an anti-migration and anti-invasion role of GBK in breast cancer cells, especially in invasive breast cancer cells.

\section{Tumor suppressor miR-31 is upregulated after GBK treatment in breast cancer cells}

Considering that some miRNAs could function as tumor suppressor and has been implicated in directly inhibiting cancer progression, they may act as specific drug target in cancer treatment. For instance, miR21 is involved in the regulation of apoptosis in breast cancer cells [7], miR-151 is found to affect the development of breast cancer through the action of DNA repair process, and miR-421 can inhibit the migration and invasion of breast cancer by targeting MTA7[8, 9].We selected nine miRNAs closely related to the occurrence and development of breast cancer based on the former research. Among the nine miRNAs selected, miR-22, miR-31, miR-411 and miR-421 function as tumor suppressor, while miR-21, miR145, miR-150, miR-182 and miR-217 could promote cancer development[10-20].

In order to determine the potential miRNA target of GBK, RT-qPCR was used to detect the expression of those miRNA in mouse serum from breast cancer xenograft mouse model after GBK treatment (Supplementary Fig. 1). However, the results showed that after treatment of GBK, the expression level of nice miRNAs in serum was slightly higher than those in control group. Although there are some changes between the experimental group and the control group, the results are not statistic significant. We then performed the experiments in breast cancer cell lines MCF-7 and SUM-159 to investigate the function of GBK on the expression of breast cancer related miRNAs. Different concentration of GBK was added to the cells for $48 \mathrm{~h}$ and miRNA expression was detection by RT-qPCR. The expression of miR-31 was consistently upregulated after GBK treatment in two breast cancer cell lines tested (Fig. 2B). The expression of other miRNAs to GBK treatment was not consistent and thus excluded for the further investigation (Fig. 2A-I).

By analyzing the expression of nine breast cancer related miRNAs, it is preliminarily indicated that the tumor suppressor effect of GBK may be closely related to miR-31.

\section{The expression level of miR-31 target genes related to cell migration is down-regulated after GBK treatment}

In previous studies, the function of miR-31 has been shown to be highly related with the progression and metastasis of breast cancer, and miR-31 exerts a fundamental role in regulating the invasion-metastasis cascade via targets genes critical in these processes, such as cytoskeletal rearrangement proteins and pivotal genes in cancer-associated fibroblasts (CAFs). RhoA, which participates in the regulation of actin 
cytoskeleton, was shown to be a direct target of miR-31[21, 22]. Moreover, another member of the Rho family, RHOBTB1, was shown to be a target of miR-31 in colon cancer[23]. WAVE3, an actin remodeling protein, was shown to be overexpressed in invasive breast cancer cells due to miR-31 down-regulation, and its expression promoted cancer cell migration and invasion[24]. Homeobox gene SATB2 was shown to be a direct target of miR-31 in CAF and involved in increasing tumor cell migration and invasion[25].

We screened nine target genes closely related to the anti-metastatic function of miR-31, monitoring their expression in SUM-159 cells after GBK treatment. The expression of RHOBTB1, RhoA, SATB2, and WAVE3 are all down-regulated after 48 hours of GBK treatment, indicating that the tumor suppressor effect of GBK may be related to invasion-metastasis related signaling pathways (Fig. 3A-I).

In order to further validate the effect of GBK on the expression of invasion-metastatic genes, western blot analysis was performed. It was demonstrated that the expression level of RhoA, WAVE3 and SATB2 was all reduced after GBK treatment (Fig. $3 \mathrm{~J}$ ). Thus, it is speculated that GBK inhibits the migration and invasion of breast cancer cells by promoting the expression of miR-31, in turn inhibiting the expression of miR-31 target genes RhoA, WAVE3 and SATB2.

\section{Expression of miR-31 and its host gene IncRNA LOC554202 is upregulated by inhibiting promoter hypermethylation after GBK treatment}

It was pointed out that miR-31 locates in the intronic sequence of long non-coding RNA (IncRNA) LOC554202, and its transcriptional activity is regulated by LOC554202 (Fig. 4A) [24]. It was also demonstrated that the major mechanisms for silencing miR-31 in triple-negative breast cancer (TNBC) is hypermethylation of the CpG island of the LOC554202 promoter region, which may become a new entry point for TNBC treatment [24].

We tested the expression of LOC554202 in ER-positive breast cancer cell lines MCF-7 and TNBC cell line SUM-159, and found that the expression of LOC554202 was up-regulated under GBK treatment (Fig. 4B and C). Then we selected two CpG sites in LOC554202 and methylation-specific PCR (MSP) technology was used to detect changes of the methylation level of these sites after GBK treatment. We found the methylation levels at CpG MSP Set2 decreased significantly under GBK treatment in a dose-dependent manner in two cell lines (Fig. 4D and E). These data indicate that GBK treatment affects the epigenetic modification at CpG sites and plays an important role in upregulating of both the LOC554202 and miR-31 genes.

\section{Combination treatment with GBK and DDP/VP-16 has synergistic and dose reduction potential in the proliferation of breast cancer cells}

The chemotherapy drugs cisplatin (DDP) and Vepeside (VP-16) are widely used as first-line therapy for metastatic breast cancer and small cell lung cancer[26, 27]. In the precious study, we demonstrated that GBK has specific inhibitory effect on breast cancer cells compared with normal breast cells and other types of cancer cells [28]. In this preclinical study, we want to evaluate the effect of GBK in combination 
with DDP/VP-16 as agents in breast cancer cells. The sensitivity of SUM-159 and MCF-7 cell lines to growth inhibition during 48 hours exposure to GBK and DDP/VP-16 was determined as single agents, and in combination at 6 concentrations between $0.1 \times$ and $4 \times$ their respective IC50 concentrations for DDP, as well as $0.2 \times$ and $4 \times$ their respective IC50 concentrations for VP-16. The effect of combined treatment was cell type dependent. The combination of DDP/VP-16 with GBK at all concentrations led to greater growth inhibition compared to either agent alone for the SUM-159 (Fig. 5A-E) and MCF-7 (Fig. 5F-J) cell lines, although the increase was smaller for the MCF-7 cells.

These results demonstrated that chemotherapy drugs DDP/VP-16 combination with GBK has synergistic and dose reduction potential in the proliferation of breast cancer cells SUM-159 and MCF-7, indicating a potential guiding significance for clinical combination treatment.

\section{Combination treatment with GBK and DDP impaired the independent viability of breast cancer cells} In colony formation experiments, colony forming rate represents the independent survival ability of cells. The representative images after crystal violet staining showed that GBK can significantly inhibit the formation of cell colonies of TNBC SUM-159 (Fig. 6A). Moreover, when combined with DDP, GBK can further inhibit the formation of cell colonies, and its inhibitory ability is positively correlated with drug concentration. After quantifying the results, it is revealed that combination treatment with GBK and DDP has a synergistic inhibitory effect on breast cancer cell colony formation (Fig. 6B).

\section{The effect of combination treatment on miR-31 target gene expression}

It has been showed that GBK treatment led to an upregulation of the expression of miR-31 and its host gene IncRNA LOC554202 in breast cancer cells when acting alone. In order to study whether the combination medication treatment with GBK and DDP can also have the same synergistic function, RTqPCR was performed to detect the target genes expression of miR-31 in SUM-159 and MCF-7 after drug treatment. It was revealed that when the cells were treated with GBK combined with DDP, the expression of SATB2 and RhoA was decreased significantly in SUM-159 cells, and there were no significant changes in expression levels of other genes (Fig. 7). It was also indicated that combination treatment has an obvious synergistic effect in SUM-159 cells than that in MCF-7 cells, meanwhile, the low concentration of GBK combined with DDP appears have better synergistic effects than high concentration counterpart (Fig. 7).

\section{Combination treatment with GBK and DDP has synergistic and dose dependent effect on the inhibition of tumor growth in vivo}

To further analyze whether the combination treatment with GBK and DDP has a clear inhibitory effect on breast cancer progression in vivo, NOD/SCID immunodeficient mice were used to construct a human breast cancer cell xenograft model by subcutaneously inoculated with SUM-159 cells. All of the mice developed subcutaneous xenografts, and then were divided into four groups and administered intraperitoneally with GBK $10 \mathrm{mg} /(\mathrm{kg} .1 \mathrm{D})$ and DDP $1 \mathrm{mg} /(\mathrm{kg} .2 \mathrm{Ds})$ in Group A, GBK $5 \mathrm{mg} /(\mathrm{kg} .1 \mathrm{D})$ and DDP $1 \mathrm{mg} /(\mathrm{kg} .2 \mathrm{Ds})$ in Group B, 0.9\% saline in group C, and DDP $1 \mathrm{mg} /(\mathrm{kg} .2 \mathrm{Ds})$ in Group D when the 
tumor volume reached $8 \mathrm{~mm}^{3}$. During 24 days of continuous injection, the notable anti-tumor effects were observed.

We found that DDP alone in group $D$ could inhibit tumor proliferation, and under the combined treatment of GBK and DDP, the tumor volume and average tumor weight of mice in group $A$ and $B$ were further reduced than those in $D$, indicating that combination treatment with drugs of DDP and GBK has synergistic and dose dependent effect on the inhibition of breast cancer cell proliferation in vivo (Fig. 8AC).

In addition, the body weight of mice in group $\mathrm{C}$ which were administered with saline increased slightly, while the body weight of mice in D that only administered with DDP decreased slightly. Interestingly the body weight of mice in group $A$ and $B$ decreased obviously with the combination treatment with DDP and GBK, and the weight loss of group A was larger than that of B (Fig. 8D). It was indicated that GBK could also perform as an antihyperlipidemic drug alone with its anti-tumor properties.

\section{Discussion}

In this study, we investigated the mechanism of GBK in impairing breast cancer cell invasion and metastasis at the cellular and molecular levels. GBK has a significant inhibitory effect on the proliferation and migration of breast cancer cells, and this inhibitory effect is positively correlated with its concentration. We also identified the main target of GBK by analyzing miRNA expression patter changes under GBK treatment. By Analyzing the expression of miRNA related to breast cancer, it was found that the expression of miR-31 was up-regulated under the treatment of GBK, and the expression of host gene LOC554202 of miR-31 was also up-regulated. Target genes of miR-31 related to cell migration and metastasis were downregulated, indicating GBK may inhibit cell migration by promoting expression of tumor suppressor gene miR-31. Moreover, we demonstrated that there are better outcomes in inhibiting the growth and migration of triple negative breast cancer cells when chemotherapy drug DDP is combined with GBK in vitro and in vivo.

Given the large number of studies that abnormal expression of miRNA is related to a variety of human diseases, it is evident that they fine-tune many biological processes. Also, miRNAs are play a part in the regulation of promoting cancer growth or conversely. Some miRNAs can be used as prognostic markers for malignant tumors, while other miRNA molecules are potential targets for cancer treatment [29]. Considering the expression of miRNAs almost affects all stages of malignant tumors: occurrence, development, metastasis and drug resistance [30] and it is relatively stable and can be detected in a variety of biological fluids, such as blood, urine, cerebrospinal fluid and saliva [31], miRNAs may become more effective biomarkers in cancer therapy.

One especially interesting cancer-related miRNA is miR-31, which is frequently altered in a large variety of cancers[32, 33]. For example, in breast cancer loss of miR-31 expression is associated with high risk of metastases[33]. Existing studies have demonstrated that miR-31 is a tumor suppressor which plays an 
important role in the occurrence and development of cancer. miR-31 directly acts on the 3'UTR region of multiple target genes like RhoA, SATB2 or WAVE3 which closely related to cell invasion, migration and proliferation. RhoA is related to the movement and migration of breast cancer cells, and it is mainly involved in the regulation of actin and microfilament skeleton polymerization [34]. The RhoA/ROCK signaling pathway play an important role in this process. In addition to directly affecting the cell microfilament skeleton polymerization, it also affects the degradation of extracellular matrix [35] and the activated Rho protein kinase (rho associated coiled coil-forming protein kinase, ROCK) can promote tumor cell invasion and metastasis [36]. SATB2 is an important nuclear matrix protein that participates in the actin cytoskeleton regulation[37]. The main targets of SATB2 are matrix metalloproteinase-3 (MMP3) and TIMP3[38]. The extracellular domain of cell adhesion factor E-cadherin can be cleaved by MMP3 directly, which facilitates the metastasis of cancer cells[39]. SATB2 also acts on the MEK5/ERK5 signaling pathway [40]. Extracellular signal-regulated kinase 5 (ERK5) is a mitogen-activated protein kinase that can induce actin cytoskeleton remodeling and then promote cell migration. WAVE3 has multiple downstream effectors. It was found that WAVE3 has intricate regulatory relationships with Aktrelated signaling pathways and NF-KB signaling pathways. The NF-KB signaling pathway is mainly involved in the degradation of extracellular matrix (ECM)[41]. Based on the existing experimental results, we indicated that these targets of miR-31 mentioned above are potential downstream effectors of GBK. Thus, we propose a possible signaling network for GBK in inhibiting the migration and invasion of breast cancer cells (Figure. 9). In this study, we have showed that GBK affected the expression of RhoA, SATB2 and WAVE3, whether the target proteins and signal pathways regulated by these three genes are also affected by GBK need to be further studied.

MiR-31 locates in the intronic sequence of IncRNA LOC554202, and its transcriptional activity is regulated by LOC554202. It was indicated that the major mechanisms for silencing miR-31 in TNBC is hypermethylation of the CpG island of the LOC554202 promoter region[24]. We demonstrated previously that the transcription of DNA methyltransferases DNMT1, DNMT3A, DNMT3B and COQ3 genes were downregulated in GBK-treated MCF-7 cells [28]. In this study, we found that the methylation levels at CpG of IncRNA LOC554202 decreased significantly under GBK treatment in a dose-dependent manner in breast cancer cell lines, indicating that GBK treatment affects the epigenetic modification at $\mathrm{CpG}$ sites by downregulating DNA methyltransferases, and plays an important role in upregulating of both the LOC554202 and miR-31 genes (Figure. 9) .

In addition, miRNAs are known to affect many cellular processes by their ability to post-transcriptionally control gene expression. But it is still important to decipher more miRNA target genes and to examine how miRNAs are regulated and their involvement in cellular functions. High-throughput bioinformatics analysis could be a better method in analyzing the mechanism of action of GBK, and also benefit for clinical applications.

Cisplatin (DDP) is an alkylating agent classified as an anti-neoplastic drug that has been extensively used in treatment of advanced breast cancer, especially in metastatic breast cancer and triple negative breast cancer. However, the great side effects limit its long-term usage. Combination treatment is an effective 
way to solve this problem. Combination treatment with GBK and DDP has synergistic and dose reduction potential in inhibiting the proliferation of breast cancer cells in vitro and in vivo, especially in TNBC cells. Moreover, the expression of miR-31 target genes SATB2 and RhoA was decreased significantly in SUM159 cells after combination treatment with GBK and DDP, indicating the effect to impair breast cancer cell migration and invasion.

In conclusion, this study analyzed the target and underlying mechanism of GBK in inhibiting breast cancer migration and invasion, especially in TNBC, and provide theoretical support for the development of GBK as an auxiliary drug for clinical treatment.

\section{Materials And Methods}

\section{Cell Strains and Cell Culture}

MCF-10A, MCF-7 and SUM-159 were purchased from National Infrastructure of Cell Line Resource of China.

MCF-10A cells were maintained in F12 medium (Gibco) supplemented with $5 \%$ horse serum (Gibco), $1 \%$ (vol/vol) penicillin/streptomycin/L-Glutamin (Gibco), $10 \mathrm{mg} / \mathrm{mL}$ insulin, $20 \mathrm{mg} / \mathrm{mL}$ EGF, $100 \mathrm{mg} / \mathrm{mL}$ Cholera Toxin and $0.5 \mathrm{mg} / \mathrm{mL}$ Hydrocortisone. SUM-159 cells were maintained in F12 medium (Gibco) supplemented with $5 \%$ fetal bovine serum (GEMINI), $1 \%$ (vol/vol) penicillin/streptomycin/L-Glutamin (Gibco), $5 \mathrm{mg} / \mathrm{mL}$ insulin and $10 \mathrm{mg} / \mathrm{mL}$ dexamethasone. MCF-7 cells were maintained in Dulbecco's Modified Eagle Medium (Gibco) supplemented with 10\% (vol/vol) fetal bovine serum (GEMINI) and 1\% (vol/vol) penicillin/streptomycin/L-Glutamin (Gibco). All cells were cultured at $37^{\circ} \mathrm{C}, 5 \% \mathrm{CO}_{2}$ in a humidified atmosphere.

\section{Reagents and Drugs}

GBK is a generous gift from Professor Gereltu Borjihan of Inner Mongolia University. The purity of Piperine is $99 \%$ detected by high pressure liquid chromatography (Supplementary Fig. 5). miRNeasy ${ }^{\circledR}$ Serum/Plasma Kit (Qiagen, USA); TransZol Up Kit (TransGene Biotechnology Co., Ltd.); Mir-XTM miRNA First-Strand Synthesis Kit (TaKara); TransScript One-Step gDNA Removal and cDNA Synthesis SuperMix Kit (TransGene Biotechnology Co., Ltd.); SYBR® Premix Ex TaqTM II Kit (TaKara); CCK-8 Kit (Beyotime Biotechnology Co., Ltd.); Crystal Violet (SIGMA); FITC Annexin V Apoptosis Detection Kit I (BD Pharmingen); Protein Antibody (Absin); Tubulin Antibody (TransGene Biotechnology Co., Ltd.); PierceTM ECL Western Blotting Substrate Kit (Thermo, USA); ELISA Kit (Wuhan Xinqidi Biotechnology Co., Ltd.); TransStart FastPfu DNA Polymerase (TransGene Biotechnology Co., Ltd., Lot: M10524); Cisplatin (DDP, Meilun Bio, Lot: D0921A); Etoposide (VP-16), United Laboratories).

\section{Primers}

The primers used in the real-time quantitative PCR (RT-qPCR) or PCR were designed by Primer 5 software and NCBI Primer-BLAST, synthesized by Shanghai Biotech (Sangon) Beijing Primer Synthesis Company, and $\mathrm{Tm}$ value fluctuated at $60^{\circ} \mathrm{C}$. Specific primers are shown in Supplementary table 1-3. 


\section{Western Blot}

Cells were seeded in 6-well plates. The cells were harvested 2 days after GBK added, washed once in PBS, and lysed in sample buffer ( $2 \%$ SDS, $0.25 \mathrm{M} \mathrm{pH} 6.8$ Tris-HCl, $20 \mathrm{mM}$ dithiothreitol, $10 \%$ glycerol, $0.1 \%$ Bromophenol blue). $20 \mathrm{\mu g}$ of protein was separated on $12 \%$ Polyacrylamide gel and transferred to a nitrocellulose membrane. Membrane was blocked for 1 hour at room temperature in blocking buffer (5\% skim milk in PBS containing $0.05 \%$ Tween-20) and then incubated with primary antibodies and peroxidase (HRP)-conjugated secondary antibody. Tubulin served as a reference protein.

\section{Cell Proliferation Ability Assay with CCK-8}

$5 \times 10^{3} / 100 \mu \mathrm{L}$ cells were seeded in a 96 -well plate and incubated at $37^{\circ} \mathrm{C}, 4 \% \mathrm{CO}_{2}$. After 24 hours, the cells were treated with GBK. After 48 hours, $10 \mu \mathrm{L}$ CCK-8 solution was added into each well and returned to the incubator for further 1.5 hours. The viability of the cells was measured using a microplate reader at the wavelength of $\mathrm{OD}_{450 \mathrm{~nm}}$.

\section{Extraction of MicroRNA from Mouse Serum Samples}

NOD/SCID mice used in this experiment were purchased from Boai Biotechnology Co., Ltd. Twelve female NOD/SCID mice aged 3-4 weeks were used to establish heterogeneous tumor models with MCF-7 breast cancer cells. Five mice were selected as the control group, and the other seven as the experimental group.

After the tumor volume reached $8 \mathrm{~mm}^{3}$, the experimental group was injected with GBK $10 \mathrm{mg} /(\mathrm{kg} .1 \mathrm{D})$, while the control group was injected with $0.9 \%$ normal saline. Serum samples were taken after 21 consecutive days.

$200 \mu \mathrm{L}$ of serum sample were taken from each mouse, 5 times volume of lysate was added, and vortexed to mix. After standing for $5 \mathrm{~min}$ at room temperature, $3.5 \mu \mathrm{L}$ of control solution was added and mixed. $200 \mu \mathrm{L}$ of chloroform was added, and vortexed for $15 \mathrm{sec}$, then standed at room temperature for $3 \mathrm{~min}$. Samples were centrifuged at $4^{\circ} \mathrm{C}, 12000 \mathrm{rpm}$ for $15 \mathrm{~min}$, then clear supernatant was transfered to a new EP tube, 1.5 times volumes of absolute ethanol and were added and vortexed to mix. All the solution was added to the adsorption column, centrifuged at room temperature, $12000 \mathrm{rpm}$ for $1 \mathrm{~min}$. $700 \mu \mathrm{L}$ of RWT buffer was added to the adsorption column, centrifuged at $12000 \mathrm{rpm}$ for $1 \mathrm{~min} .500 \mu \mathrm{L}$ of RPE buffer was added to the adsorption column, centrifuged at $12000 \mathrm{rpm}$ for $1 \mathrm{~min} .500 \mu \mathrm{L}$ of $80 \%$ ethanol was added to the adsorption column, centrifuged at $12000 \mathrm{rpm}$ for $2 \mathrm{~min}$. The adsorption column was placed on a new collection tube, centrifuged at $12000 \mathrm{rpm}$ for $5 \mathrm{~min} .14 \mu \mathrm{L}$ of RNase-free water was added to the adsorption column and standed for $1 \mathrm{~min}$, then centrifuged at $12000 \mathrm{rpm}$ for $1 \mathrm{~min}$. The extracted RNA can be stored at $-80^{\circ} \mathrm{C}$ until use.

\section{Relative Quantitative Real-Time PCR}

Extraction of total RNA from cell lines was carried out according to the TransZol Up Kit instruction. Reverse transcription PCR was performed using TransScript One-Step gDNA Removal and cDNA Synthesis SuperMix Kit (TransGene Biotechnology Co., Ltd.), and quantitative real-time PCR was 
performed using SYBR® Premix Ex TaqTM II Kit (TaKara). GAPDH gene served as a reference. Gene expression was measured in triplicates.

\section{Wound Healing Assay}

Cells were seeded into 6-well tissue culture plate. When the cell density reached $100 \%$, scratching and photographing were performed. Replaced old medium with the $1 \%$ low-serum medium and continue to culture cells in incubator after drugs were added. Photos were taken every 12 hours on an inverted microscope. The gap distance can be evaluated using Image $\mathrm{J}$ software to calculate the cell migration rate.

\section{Cell invasion experiment}

The subpackaged matrix glue (Corning, US) taken out from $-20^{\circ} \mathrm{C}$ was quickly diluted ten times with serum-free medium on ice. $100 \mu \mathrm{L}$ diluted matrix glue was laid on the upper and lower surface of Transwell chamber in 24-well plate, and then it was incubated at $37^{\circ} \mathrm{C}$ for 1 h. $5 \times 10^{5}$ cells $/ \mathrm{mL}$ suspension was prepared and $200 \mu \mathrm{L}$ was added to each chamber, simultaneously, $600 \mu \mathrm{L}$ medium with $5 \%$ FBS was added into the lower layer of Transwell chamber. Make sure that there were no bubbles at the bottom of the upper chamber and incubate whole plate at $37^{\circ} \mathrm{C}$ for $24 \mathrm{~h}$. Gently rotate the cotton swab to wipe the upper chamber and carefully wipe off the sidewall cells. $600 \mu \mathrm{L} 4 \%$ PFA was added into each lower chamber and fixed at room temperature for $20 \mathrm{~min}$. After the PFA was washed off by PBS, 600 $\mu \mathrm{L} 0.1 \%$ crystal violet was added into the downward chamber, and dyed in dark for $30 \mathrm{~min}$ at room temperature. Then, the chamber was taken out and washed with PBS, the number of cells transferred to the lower surface of the chamber was counted under the microscope.

\section{Cell Colony Formation Assay}

$1 \times 10^{3}$ cells were seeded into 6 -well plate. After being cultured for 24 hours in an incubator, potassium piperonate (GBK), cisplatin (DDP) and etoposide (VP-16) were added with a concentration gradient for further 7-14 days. Then, $1 \mathrm{~mL} 4 \%$ PFA was added to each well for 15 minutes, cells were rinsed with $1 \mathrm{ml}$ PBS, and $500 \mu \mathrm{L} 0.01 \%$ crystal violet was added to each well for 15 minutes. The plates were dried and the colonies were counted.

\section{Methylation specific PCR (MSP)}

Preparation of bisulfite-modified DNA for methylation analysis was under the instructions of the EZ DNA Methylation-Gold ${ }^{\text {TM }}$ kit (Zymo Research). In brief, CT Conversion Reagent and M-Wash Buffer were preparated prior to use. Genomic DNA (200 ng in $20 \mu \mathrm{L}$ ) was conversed by $130 \mu \mathrm{L}$ CT Conversion Reagent in a PCR cycler, performing $98^{\circ} \mathrm{C}$ for 10 mins, $64^{\circ} \mathrm{C}$ for $2.5 \mathrm{~h}, 4^{\circ} \mathrm{C}$ storage up to $20 \mathrm{~h} .600 \mu \mathrm{L}$ of M-Binding Buffer was added and washed with M-Wash Buffer one time. $200 \mu \mathrm{L}$ M-Desulphonation Buffer was added, and then standed at RT for 20 mins and washed with M-Wash Buffer twice. $10 \mu \mathrm{L}$ of doubledistilled water was added and centrifuged, the DNA was resuspended.

MSP was performed on bisufite-converted DNA using the special primer pairs described in Supplementary table 3 Primer list III. Every genomic DNA sample was amplified using either the unmethylated or the 
methylated primer pairs. The PCR products were next separated by agarose electrophoresis and their densitometry would demonstrate the intensities of the PCR products between the methylated and unmethylated primer-pairs.

\section{NOD/SCID Mouse Tumor Xenograft Model}

The mouse model was derived from Jennio Biotechnology company. Twenty immunodeficient female mice between 3 and 4 weeks were used to establish a NOD/SCID mouse xenograft model. $100 \mu$ of prepared $2 \times 10^{6} / 100 \mu \mathrm{L}$ MCF-7 cells suspension was injected into the hind leg of NOD/SCID mice, 5 nude mice were selected randomly as the control group, and the other 15 nude mice were divided into 3 experimental groups randomly. The body weight of mice was measured every 3 days after injection. When the tumor mass grew to $8 \mathrm{~mm}^{3}$, the drugs or $0.9 \%$ saline was injected into nude mice. Weight and the tumor volume measured with a vernier caliper were recorded every 3 days. The tumor volume was calculated according to the following formula: $V=\left(a b^{2}\right) / 2$ ("a" represents the longest diameter of the tumor and " $b$ " represents the shortest). After 20 days, the tumor-bearing mice were killed, the tumor lumps were removed and weighed.

\section{Statistical Analysis}

Data are presented as the mean \pm SE from three independent experiments, and all statistical analyses were performed using a Student's t test with SPSS 19.0 software (SPSS Inc., Chicago, IL, USA).

Significant differences were accepted when ${ }^{*} P<0.01$, ${ }^{*} P<0.001$, and ${ }^{* * *} P<0.0001$.

\section{Ethics approval and consent to participate}

Investigation has been conducted in accordance with the ethical standards and according to the Declaration of Helsinki,ARRIVE guidelines and according to the national and international guidelines. All experiments adhered with the National Research Council Guide for the Care and Use of Laboratory Animals and were approved by the Institutional Animal Care and Use Committee at Inner Mongolia University.

\section{Abbreviations}

miRNAs \MicroRNAs

GBK囚potassium piperate

GBN囚iperlonguminine

GBOヌpiperine

ncRNAs $\llbracket$ non-coding RNA

IncRNA: long non-coding RNA

CLL囚chronic lymphocytic leukemia 
DNMT18DNA methyltransferases-1

ROS『reactive oxygen species

RT-qPCR \real-time quantitative polymerase chain reaction

TNBC: triple-negative breast cancer

MSP: methylation-specific PCR

ELISA: Enzyme linked immunosorbent assay

MMP3: matrix metalloproteinase-3

ECM: extracellular matrix

ERK5: Extracellular signal-regulated kinase 5

DDP $₫$ Cisplatin

VP-16囚etoposide

ROCK『rho associated coiled coil-forming protein kinase

PBS: phosphate buffered solution

CCK-8: Cell Counting Kit-8

PFA: Paraformaldehyde

MSP: Methylation specific PCR

\section{Declarations}

\section{Author Contributions:}

Data curation, Lifei Fan and Morigen; funding acquisition, Lifei Fan; investigation, Xiaoxia Tian and Junping Lu; methodology, Mailisu.

\section{Consent to Publish:}

Not Applicable.

\section{Funding:}

This work was supported by grants from the National Natural Science Foundation of China (NSFC Grant no. 31700034 and 31960162 to Lifei Fan), the Program for Young Talents of Science and Technology in 
Universities of Inner Mongolia Autonomous Region (Grant no. NJYT-17-B03 to Lifei Fan) and the Natural Science Foundation of Inner Mongolia (Grant no. 2017MS0331 to Lifei Fan).

\section{Acknowledgments:}

GBK is a generous gift from Professor Gereltu Borjihan of Inner Mongolia University.

\section{Conflicts of Interest:}

The authors declare no conflict of interest.

\section{Availability of Data and Materials:}

If someone wants to request the data from this study, he can contact Lifei Fan (lifei.fan@imu.edu.cn).

\section{References}

1. Ma, L., Teruya-Feldstein, J., and Weinberg, R.A.J.N. Tumour invasion and metastasis initiated by microRNA-10b in breast cancer. Nature. 2007;449, 256-256.

2. Nazarov, P.V., Reinsbach, S.E., Muller, A., Nicot, N., Philippidou, D., Vallar, L., and Kreis, S. Interplay of microRNAs, transcription factors and target genes: linking dynamic expression changes to function. Nucleic Acids Resl. 2013; 41, 2817-2831.

3. Kurozumi, S., Yamaguchi, Y., Kurosumi, M., Ohira, M., Matsumoto, H., and Horiguchi, J.J.J.o.H.G. Recent trends in microRNA research into breast cancer with particular focus on the associations between microRNAs and intrinsic subtypes. Journal of Human Genetics.2016

4. Identification of miR-10b, miR-26a, miR-146a and miR-153 as potential triple-negative breast cancer biomarkers. Cellular Oncology. 2015; 38, 433-442.

5. O'Day, E., and Lal, A.J.B.C.R. MicroRNAs and their target gene networks in breast cancer. Breast Cancer Research. 2010;12, 1-10.

6. Jin, Z., Borjihan, G., Zhao, R., Sun, Z., Hammond, G.B., and Uryu, T. Antihyperlipidemic compounds from the fruit of Piper longum L. Phytotherapy research. 2009;PTR 23, 1194-1196.

7. Frankel, L.B., Christoffersen, N.R., Jacobsen, A., Lindow, M., Krogh, A., and Lund, A.H. Programmed cell death 4 (PDCD4) is an important functional target of the microRNA miR-21 in breast cancer cells. J Biol Chem. 2008; 283, 1026-1033.

8. Tommasi, S., Pinto, R., Danza, K., Pilato, B., Palumbo, O., Micale, L., and De Summa, S. miR-151-5p, targeting chromatin remodeler SMARCA5, as a marker for the BRCAness phenotype. Oncotarget. 2016; 7, 80363-80372.

9. Pan, Y., Jiao, G., Wang, C., Yang, J., and Yang, W. MicroRNA-421 inhibits breast cancer metastasis by targeting metastasis associated 1. Biomed Pharmacother. 2016; 83, 1398-1406.

10. Patel, B, J., Appaiah, N, H., Burnett, M, R., Bhat-Nakshatri, Wang, Mehta, and Oncogene, B.J. Control of EVI-1 oncogene expression in metastatic breast cancer cells through microRNA miR-22. Oncogene. 
$2011 ; 30(11): 1290-1301$.

11. Koufaris, C., Valbuena, G.N., Pomyen, Y., Tredwell, G.D., Nevedomskaya, E., Lau, C.H., Yang, T., Benito, A., Ellis, J.K., and Keun, H.C.J.O. Systematic integration of molecular profiles identifies miR-22 as a regulator of lipid and folate metabolism in breast cancer cells. Oncogene.2016.

12. Ivanov, S.V., Goparaju, C.M.V., Lopez, P., Zavadil, J., Toren-Haritan, G., Rosenwald, S., Hoshen, M., Chajut, A., Cohen, D., and Pass, H.I.J.J.o.B.C. Pro-tumorigenic Effects of miR-31 Loss in Mesothelioma. Journal of Biological Chemistry. 2010; 285.

13. Zhang, Y., Xu, G., Liu, G., Ye, Y., Zhang, C., Fan, C., Wang, H., Cai, H., Xiao, R., Huang, Z.J.B., et al. miR411-5p inhibits proliferation and metastasis of breast cancer cell via targeting GRB2. Biochemical \& Biophysical Research Communications.2016; 607-613.

14. Pan, Y., Jiao, G., Wang, C., Yang, J., Yang, W.J.B., and Pharmacotherapie. MicroRNA-421 inhibits breast cancer metastasis by targeting metastasis associated 1. Biomedicine \& pharmacotherapy =: Biomedecine \& pharmacotherapie. 2016; 83, 1398-1406.

15. Badr, F.M.J.B., and Bioengineering. Potential Role of miR-21 in Breast Cancer Diagnosis and Therapy. Biotechnology and Bioengineering. 2016;3, 1068.

16. Yanling, D., Chunfu, Z., Jiahui, Z., Nannan, Z., Tao, L., Jie, F., Yi, Z., Feiyang, Z., Zehua, T., and Shengnan, T.J.I.J.o.O. miR-145 inhibits proliferation and migration of breast cancer cells by directly or indirectly regulating TGF- $\beta 1$ expression. International Journal of Oncology. 2017; 50, 1701.

17. Hu, J., Guo, H., Li, H., Liu, Y., Liu, J., Chen, L., Zhang, J., and Zhang, N.J.P.O. MiR-145 Regulates Epithelial to Mesenchymal Transition of Breast Cancer Cells by Targeting Oct4. PLoS ONE. 2012; 7(9):e45965.

18. Ar, P., Xue, L., Sudipta, P., Kalra, K., and Bose, S. Differential Expression of miR-21, miR-205, miR-221, miR-222, and miR-150 in Molecular Subtypes of Breast Cancer. In USCAP-2013. 2013.

19. Zhang, X., Ma, G., Liu, J., and Zhang, Y.J.O.L. MicroRNA-182 promotes proliferation and metastasis by targeting FOXF2 in triple-negative breast cancer. Oncology Letters. 2017.

20. Zhou, W., Song, F., Wu, Q., Liu, R., Wang, L., Liu, C., Peng, Y., Mao, S., Feng, J., and Chen, C.J.P.O. miR217 inhibits triple-negative breast cancer cell growth, migration, and invasion through targeting KLF5. PLOS ONE. 2017.

21. Chang, K.W., Kao, S.Y., Wu, Y.H., Tsai, M.M., Tu, H.F., Liu, C.J., Lui, M.T., and Lin, S.C.J.O.O. Passenger strand miRNA miR-31 regulates the phenotypes of oral cancer cells by targeting RhoA. Oral Oncology. 2013; 49, 27-33.

22. Mizoguchi, F., Murakami, Y., Research, T.S.J.A., and Therapy. miR-31 controls osteoclast formation and bone resorption by targeting RhoA. Arthritis Research \& Therapy. 2013;15.

23. Xu, R.-S., Wu, X.-D., Zhang, S.-Q., Li, C.-F., Yang, L., Li, D.-D., Zhang, B.-G., Zhang, Y., Jin, J.-P., and Zhang, B.J.I.J.o.O. The tumor suppressor gene RhoBTB1 is a novel target of miR-31 in human colon cancer. International Journal of Oncology. 2013; 42, 676-682.

24. Augoff, K., McCue, B., Plow, E.F., and Sossey-Alaoui, K. miR-31 and its host gene IncRNA LOC554202 are regulated by promoter hypermethylation in triple-negative breast cancer. Mol Cancer. 2012; 11, 5. 
25. Olga, Aprelikova, Xiang, Yu, John, Palla, Bih-Rong, Wei, Simone, and Cycle, J.J.C. The role of miR-31 and its target gene SATB2 in cancer-associated fibroblasts. Cell Cycle. 2010; Nov 1;9(21):4387- 98.

26. Sledge, G.W., Loehrer, P.J., Roth, B.J., and Einhorn, L.H.J.J.o.C.O. Cisplatin as first-line therapy for metastatic breast cancer. Journal of Clinical Oncology. 1988; 6, 1811-1814.

27. Anastasatu, C., Burnea, D., lancovici, O., Avramescu, D., and Burnea-Cornetti, R.J.P.R.S.R.D.P. [Vepeside (VP-16-213) in the treatment of bronchopulmonary cancer (preliminary data)]. Pneumoftiziologia Revista Societătii Române De Pneumoftiziologie. 1987; 36, 41-56.

28. Fan, L., Cao, X., Yan, H., Wang, Q., Tian, X., Zhang, L., He, X., Borjihan, G., and Morigen. The synthetic antihyperlipidemic drug potassium piperate selectively kills breast cancer cells through inhibiting G1S-phase transition and inducing apoptosis. Oncotarget. 2017; 8, 47250-47268.

29. Chua, J.H., Armugam, A., and Jeyaseelan, K. MicroRNAs: Biogenesis, function and applications. Curr Opin Mol Ther. 2009; 11, 189-199.

30. Acunzo, M., Romano, G., Wernicke, D., and Croce, C.M. MicroRNA and cancer--a brief overview. Adv Biol Regul. 2015; 57, 1-9.

31. Zendjabil, M., Favard, S., Tse, C., Abbou, O., and Hainque, B. [The microRNAs as biomarkers: What prospects?]. C R Biol.2017; 340, 114-131.

32. Slaby, O., Svoboda, M., Fabian, P., Smerdova, T., Knoflickova, D., Bednarikova, M., Nenutil, R., and Vyzula, R.J.O. Altered Expression of miR-21, miR-31, miR-143 and miR-145 Is Related to Clinicopathologic Features of Colorectal Cancer. Oncology. 2007; 72, 397-402.

33. Laurila, E.M., Kallioniemi, A.J.G., Chromosomes, and Cancer. The diverse role of miR-31 in regulating cancer associated phenotypes. Genes, Chromosomes and Cancer. 2013;52.

34. Ogino, Y., Liang, R., Mendonca, D.B., Mendonca, G., Nagasawa, M., Koyano, K., and Cooper, L.F. RhoAMediated Functions in C3H10T1/2 Osteoprogenitors Are Substrate Topography Dependent. J Cell Physiol. 2016; 231, 568-575.

35. Undem, C., Rios, E.J., Maylor, J., and Shimoda, L.A. Endothelin-1 augments $\mathrm{Na}(+) / \mathrm{H}(+)$ exchange activity in murine pulmonary arterial smooth muscle cells via Rho kinase. PLoS One.2012; 7, e46303.

36. Seo, C.H., Furukawa, K., Montagne, K., Jeong, H., and Ushida, T. The effect of substrate microtopography on focal adhesion maturation and actin organization via the RhoA/ROCK pathway. Biomaterials.2011; 32, 9568-9575.

37. Luo, L.J., Yang, F., Ding, J.J., Yan, D.L., Wang, D.D., Yang, S.J., Ding, L., Li, J., Chen, D., Ma, R., et al. MiR-31 inhibits migration and invasion by targeting SATB2 in triple negative breast cancer. Gene. 2016; 594, 47-58.

38. Aprelikova, O., Yu, X., Palla, J., Wei, B.R., John, S., Yi, M., Stephens, R., Simpson, R.M., Risinger, J.I., Jazaeri, A., et al. The role of miR-31 and its target gene SATB2 in cancer-associated fibroblasts. Cell Cycle. 2010; 9, 4387-4398.

39. Lochter, A., Galosy, S., Muschler, J., Freedman, N., Werb, Z., and Bissell, M.J. Matrix metalloproteinase stromelysin-1 triggers a cascade of molecular alterations that leads to stable epithelial-to- 
mesenchymal conversion and a premalignant phenotype in mammary epithelial cells. J Cell Biol.1997; 139, 1861-1872.

40. Mansour, M.A., Hyodo, T., Ito, S., Kurita, K., Kokuryo, T., Uehara, K., Nagino, M., Takahashi, M., Hamaguchi, M., and Senga, T. SATB2 suppresses the progression of colorectal cancer cells via inactivation of MEK5/ERK5 signaling. FEBS J. 2015; 282, 1394-1405.

41. Davuluri, G., Augoff, K., Schiemann, W.P., Plow, E.F., and Sossey-Alaoui, K. WAVE3-NFkappaB interplay is essential for the survival and invasion of cancer cells. PLoS One.2014; 9, e110627.

Figures 
A MCF-7

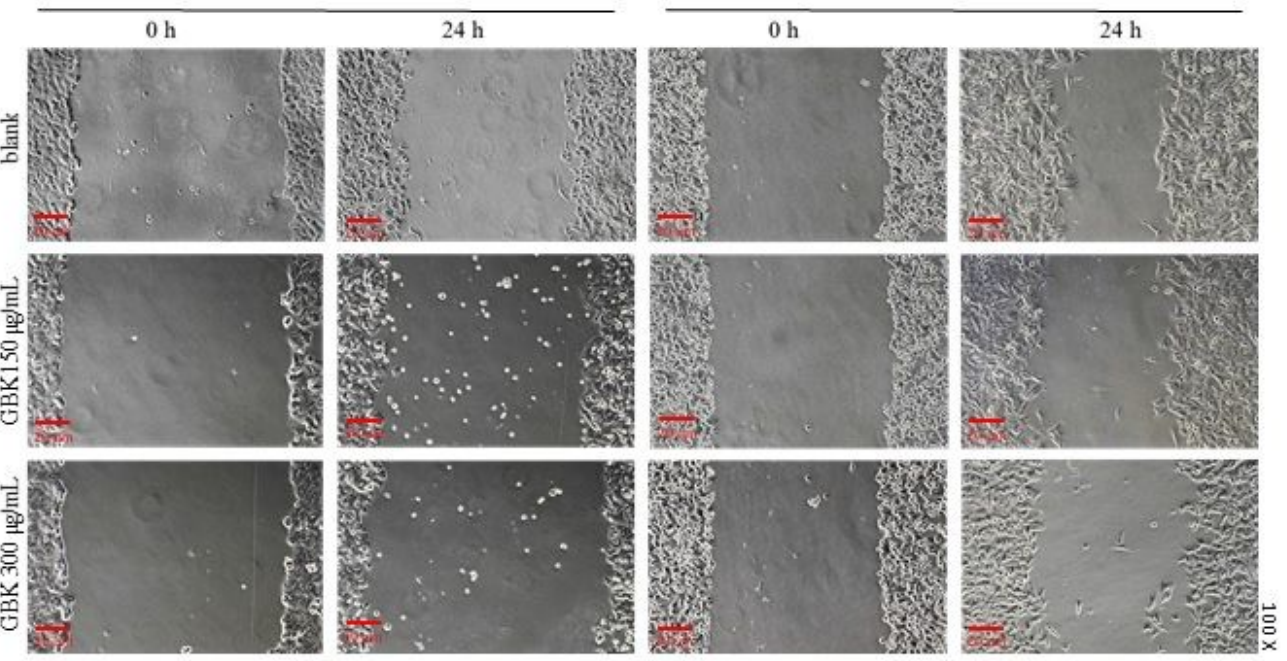

B

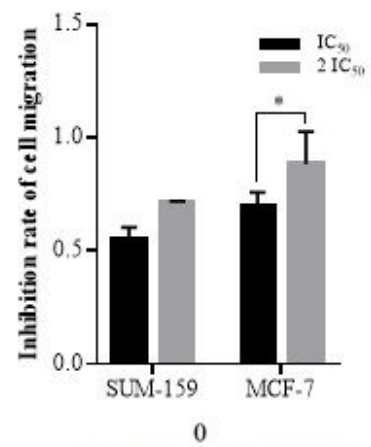

$\mathrm{C}$

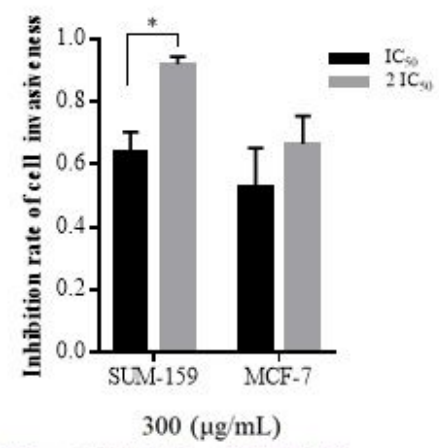

D

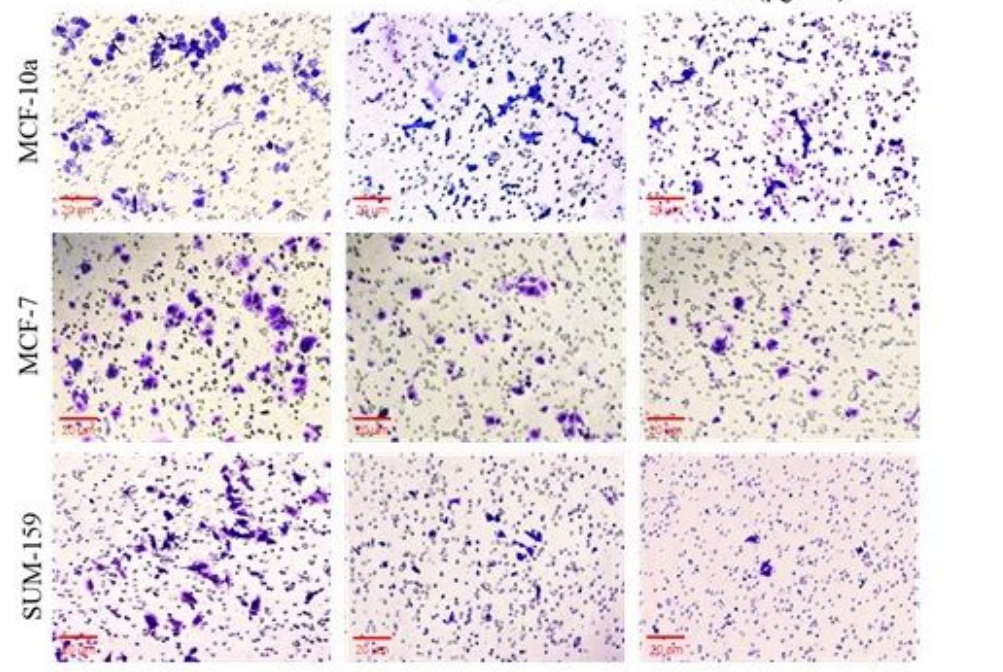

\section{Figure 1}

GBK impairs the migration and invasion ability of breast cancer cells (A) MCF7 and SUM159 cells were scratched and treated with different concentrations of GBK, cell images were captured after 24 hours (original magnification, $\times 10$, scale bar (black) as shown). IC50 represents $150 \mu \mathrm{g} / \mathrm{mL} \mathrm{GBK}$. (B) The cell mobility was analyzed by Image $\mathrm{J}$ software. Cell motility $=$ ( $\mathrm{t} 0 \mathrm{~h}$ scratch width $-\mathrm{t} 24 \mathrm{~h}$ scratch width)/ t0 $\mathrm{h}$ scratch width. Inhibition rate of cell migration by GBKIC50 = (GBK0 cell motility- GBKIC50 cell motility)/ 
GBKO cell motility. (C-D) Cell invasion under GBK treatment was investigated by Matrigel invasion assay. Photos of representative fields are shown in (D). Cell numbers were calculated in five different fields. Inhibition rate of cell invasion by GBKIC50 $=$ (GBK0 cell number- GBKIC50 cell number)/ GBK0 cell number. Data are presented as mean \pm s.e.m. of three independent experiments. Student's t test, * $p<0.01$, $\star * p<0.001, * \star * p<0.0001$.
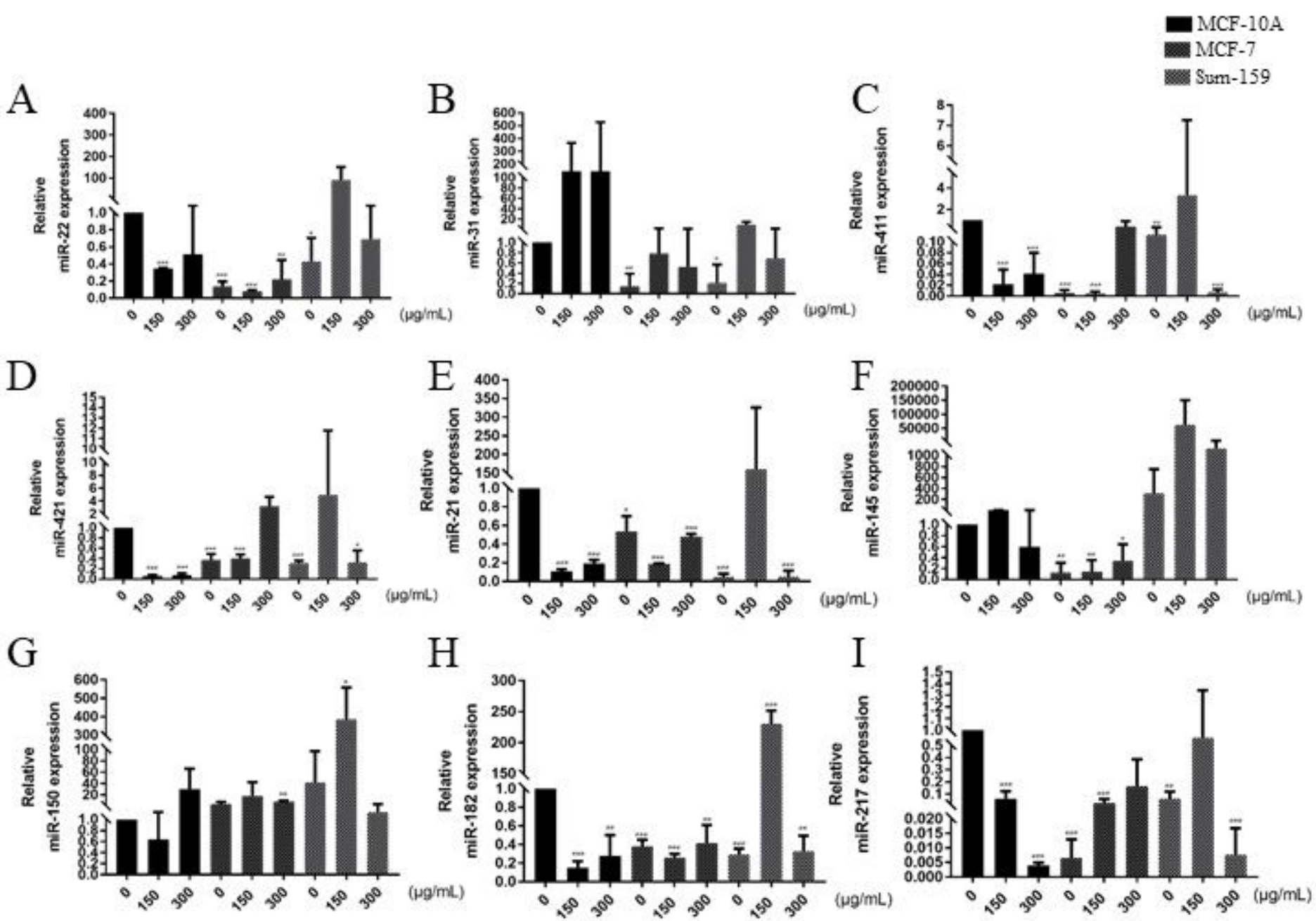

Figure 2

Expression changes of nine miRNAs in three different breast cell lines after GBK treatment MCF-10A, MCF-7 and SUM-159 cells were treated with different concentration of GBK. Total RNA was extracted after 48 hours for miRNA expression detection by RT-qPCR. (A-l) Expression quantification of miR-22, miR31, miR-411, miR-421, miR-21, miR-145, miR-150, miR-182 and miR-217 in three different breast cells after application of different concentrations of GBK. Data are presented as mean \pm s.e.m. of three independent experiments. Student's t test, ${ }^{*} p<0.05,{ }^{\star \star} p<0.01, * \star \star ~ p<0.001$. 


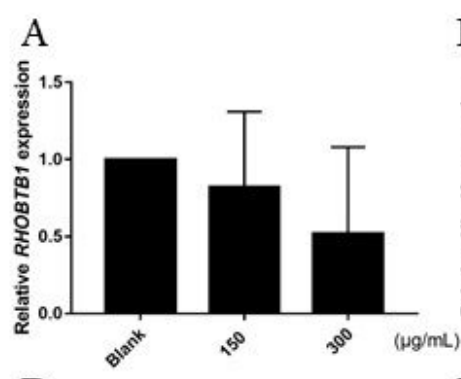

B C
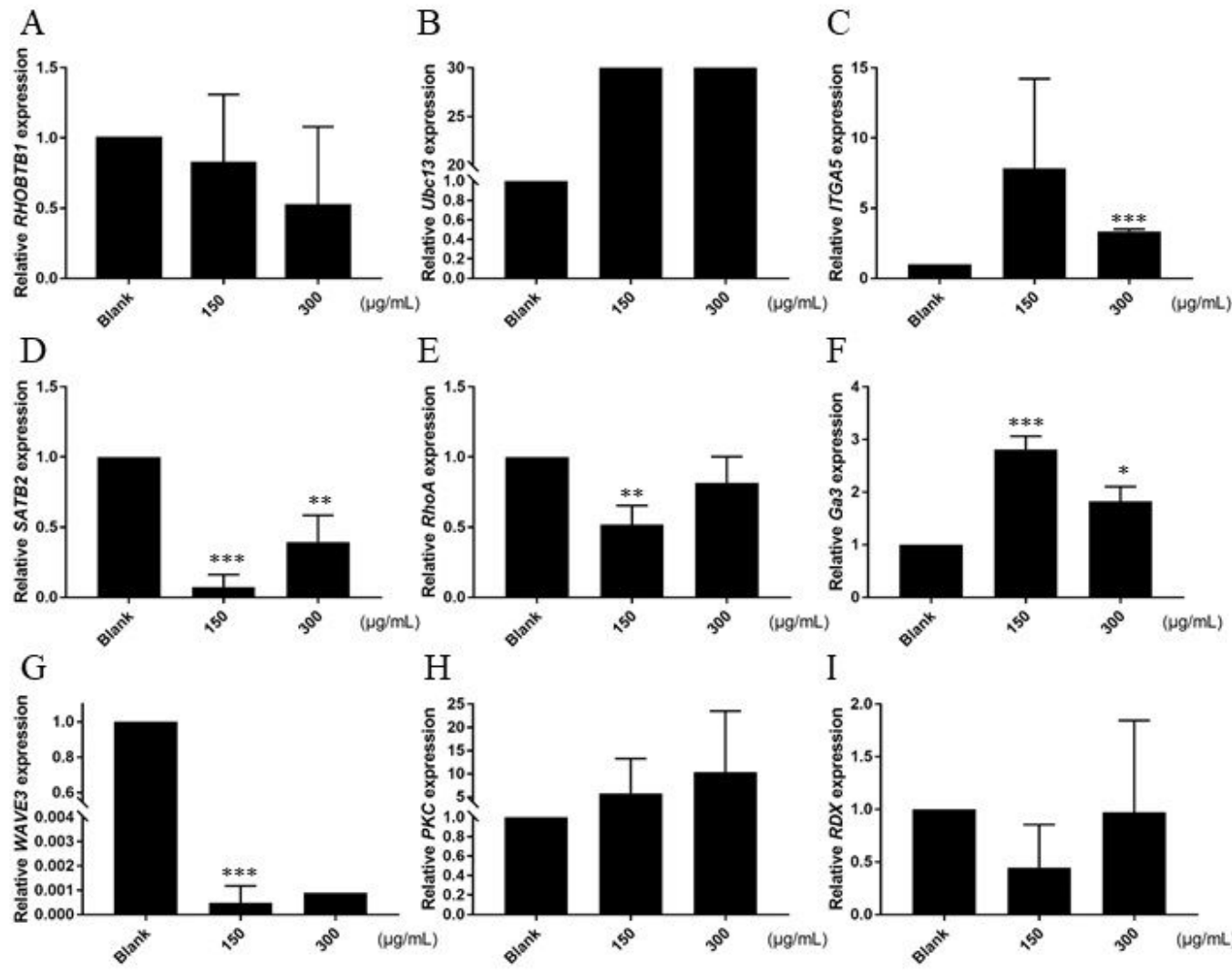

I
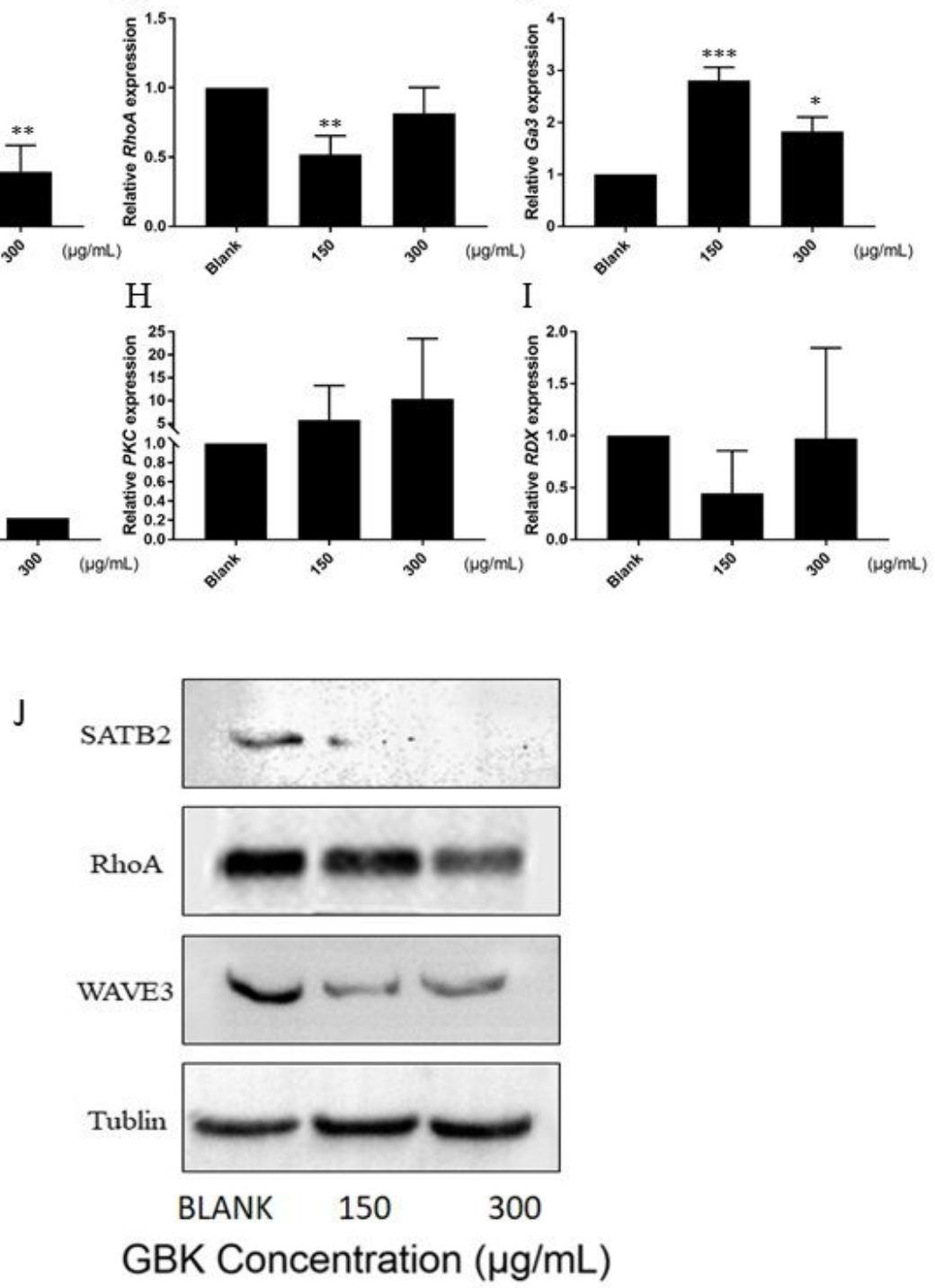

\section{Figure 3}

Detection of miR-31 target genes expression under the treatment of GBK in SUM-159 cells. (A-I) Expression of RHOBTB1, Ubc13, ITGA5, SATB2, RhoA, Ga13,WAVE3,PKC and RDX in SUM-159 cells after treatment with different concentrations of GBK was analyzed by RT-qPCR. Data are presented as mean \pm s.e.m. of three independent experiments. Student's t test, * $p<0.05, \star \star p<0.01, \star \star \star ~ p<0.001$. (J) Protein 
expression levels of miR-31 target genes related to cell migration and invasion in SUM-159 cells after GBK treatment. Cell lysates were analyzed by western blot. $\beta$-tubulin was used as an internal control.

A
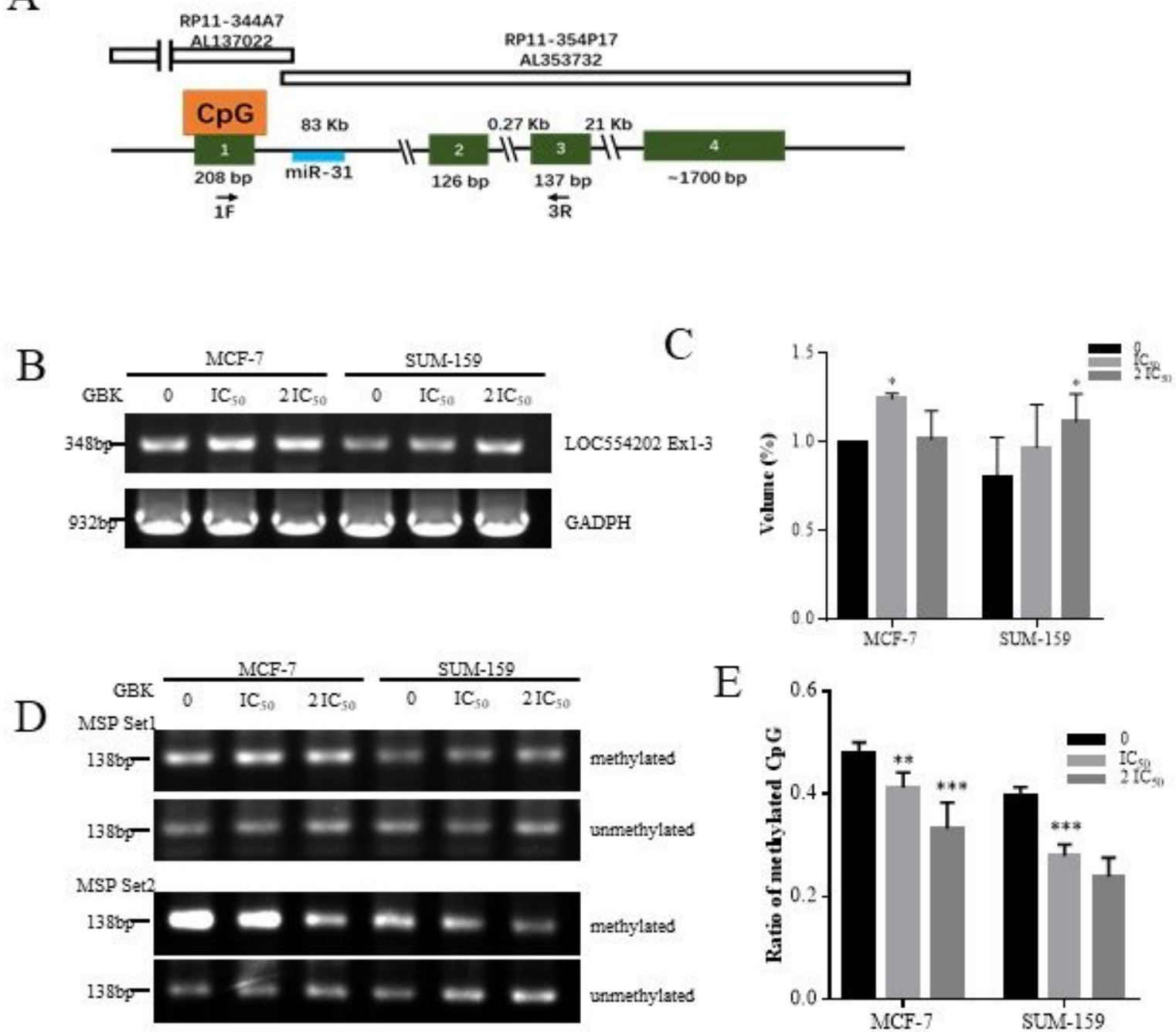

E

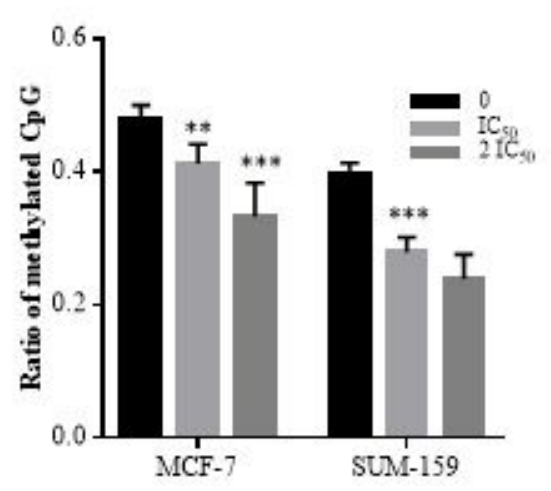

$\mathrm{F}$

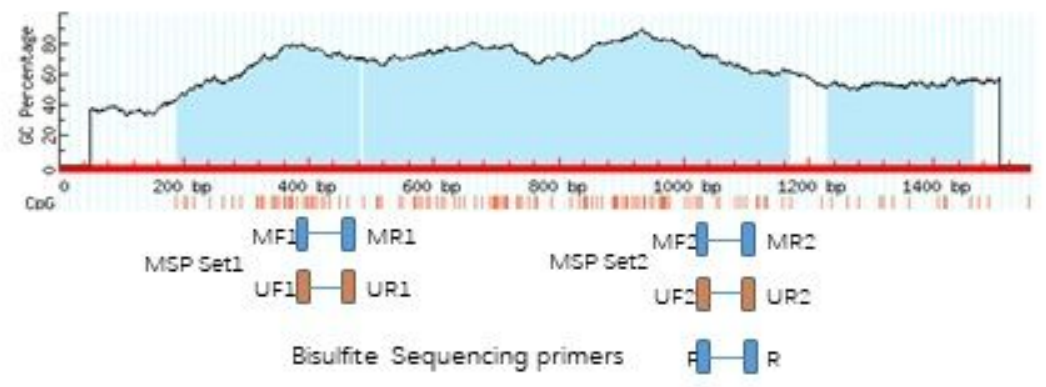

Figure 4

LOC554202 expression and its promoter hypermethylation are modified under the treatment of GBK in MCF-7 and SUM-159 cells (A) Schematic representation of the genomic organization of the LOC554202 gene (Modified from[24]). (B) Semi-quantitative RT-PCR of the LOC554202 transcript in MCF-7 and SUM- 
159 cells. GAPDH was used as an internal control. Quantitative analysis figure was shown in (C). (D) Hypermethylation of two CpG sites in LOC554202 promoter was detected by Methylation specific PCR (MSP) in MCF7 and SUM-159 cells. Bisulfite-modified DNA of the indicated samples was detected using 2 sets of primers. (E) Ratio of methylation over all $\mathrm{CpGs}$ (including methylated and unmethylated) by sequencing of bisulfite-modified DNA using Set2 primer. (F) The location of the bisulfite sequencing primers (Modified from[24]). Data are presented as mean \pm s.e.m. of three independent experiments. Student's t test, ${ }^{*} p<0.05, * * p<0.01, * \star * p<0.001$.
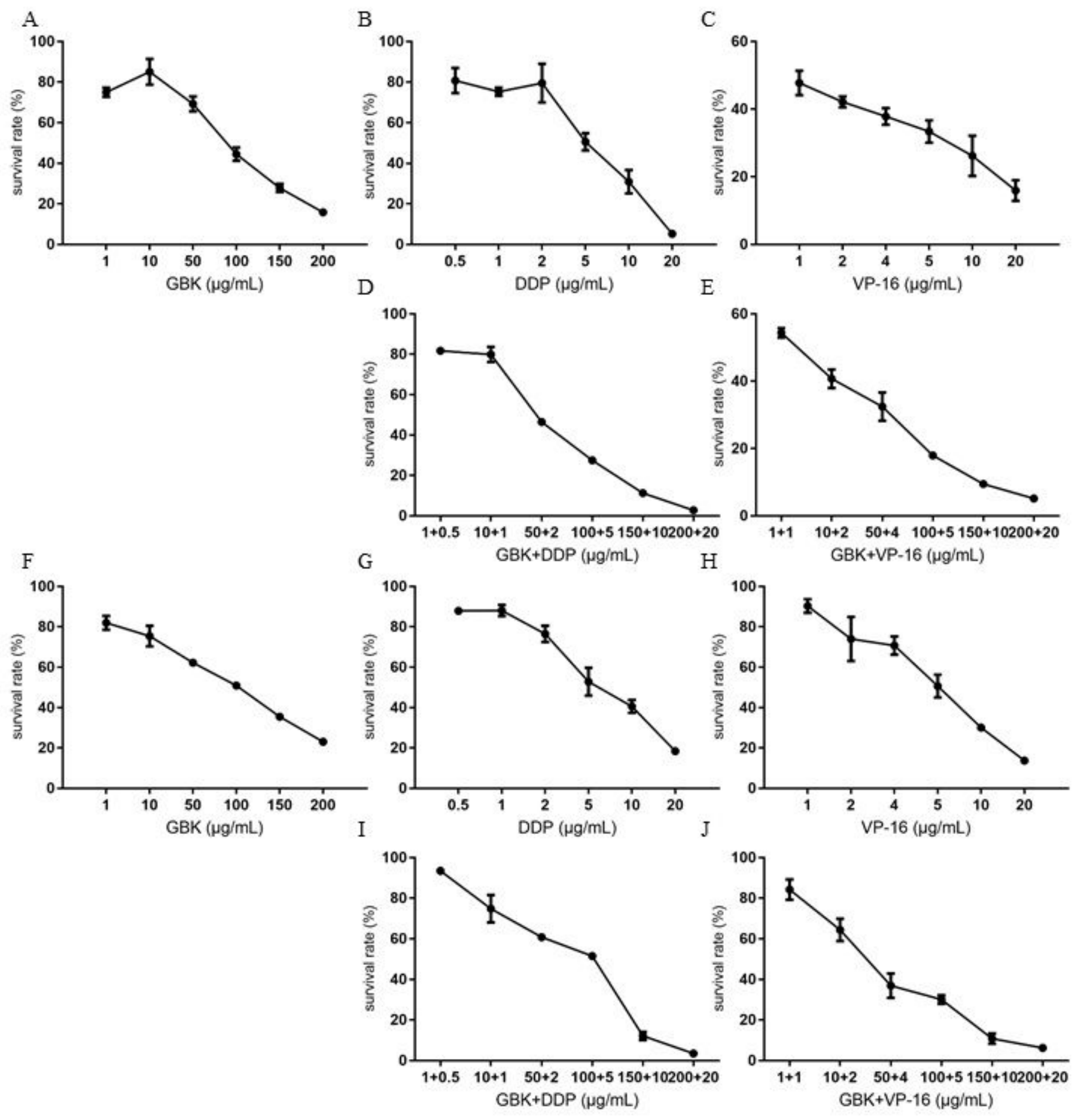


\section{Figure 5}

Combination treatment with GBK and DDP/VP-16 has synergistic and dose reduction potential in the proliferation of breast cancer cells The growth inhibition assay with drug treatment was carried out by using CCK-8 Kit, and the cell survival rate was measured after the drug administration for 48 hours. The sensitivity of SUM-159 and MCF-7 cell lines to growth inhibition during 48 hours exposure to GBK and DDP/VP-16 was determined as single agents, and in combination at 6 concentrations between $0.1 \times$ and $4 \times$ their respective IC50 concentrations for DDP, as well as $0.2 \times$ and $4 \times$ their respective IC50 concentrations for VP-16. The survival rate of SUM-159 under different concentrations of (A) GBK, (B) DDP, (C) VP-16, (D) DDP and GBK, (E) VP-16 and GBK was showed on the top panel. The survival rate of MCF-7 under different concentrations of (F) GBK, (G) DDP, (H) VP-16, (I) DDP and GBK, (J) VP-16 and GBK was showed on the bottom panel. Data are presented as mean \pm s.e.m. of three independent experiments. 


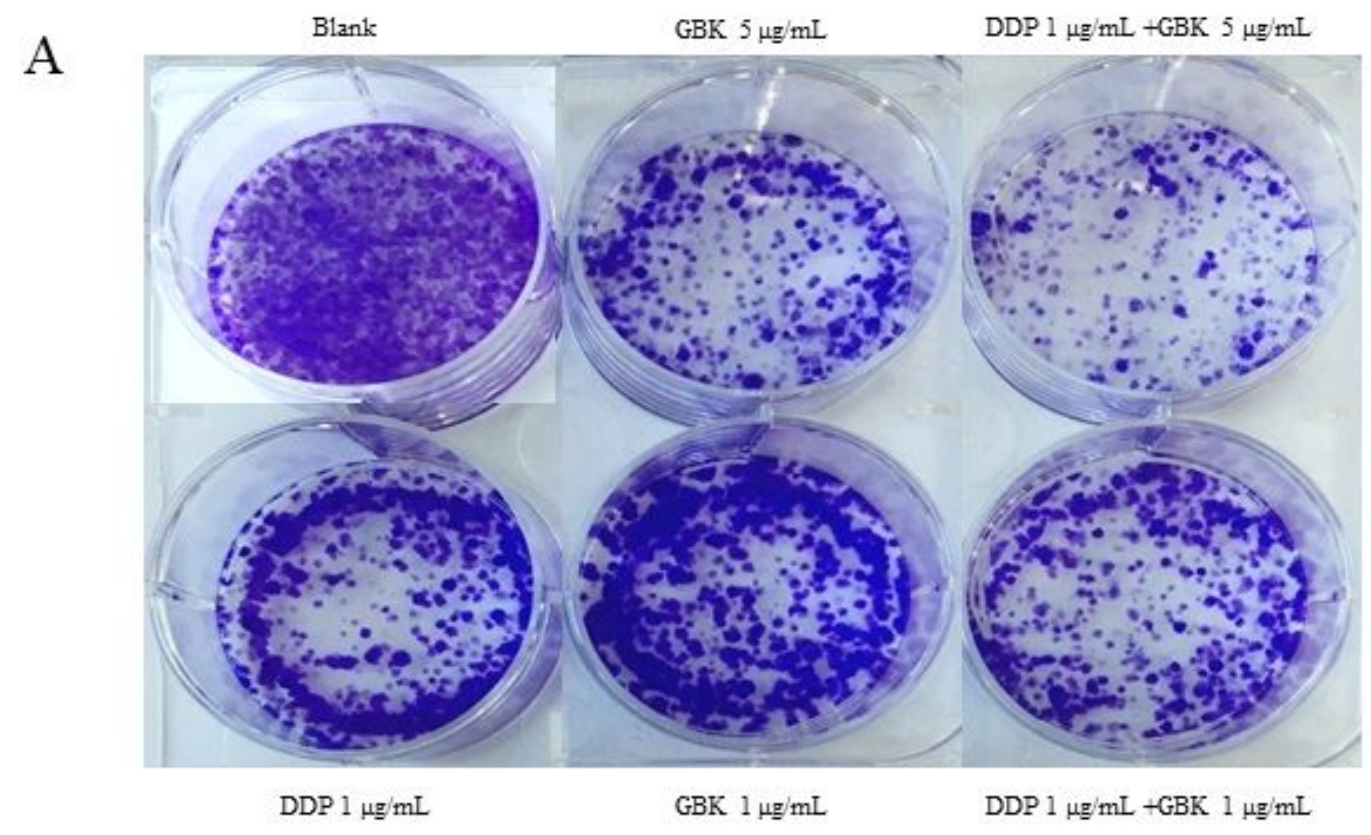

B

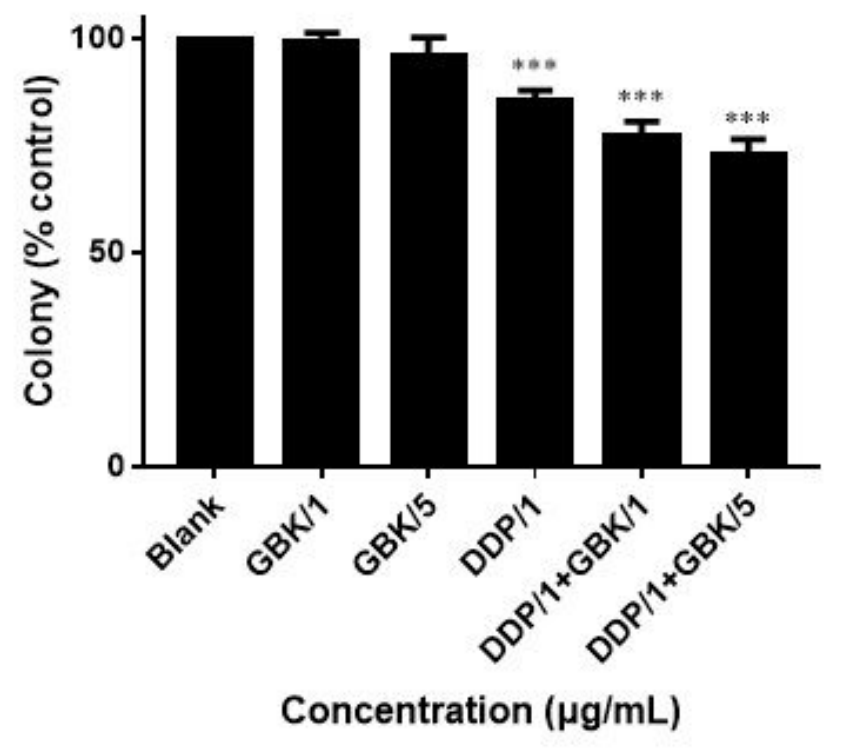

\section{Figure 6}

Combination treatment with GBK and DDP impaired the independent viability of breast cancer cells The effect of combination treatment on the progression of colony formation of breast cancer cells was analyzed by colony formation assay. (A) Cell viability was determined by crystal violet staining in SUM159 cells (B) Quantification results of $(A)$. Data are presented as mean \pm s.e.m. of three independent experiments. Student's t test, ${ }^{*} p<0.01,{ }^{* *} p<0.001,{ }^{* * *} p<0.0001$. 
RHOBTB1

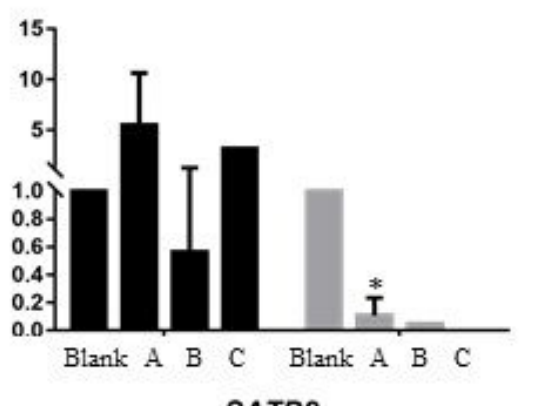

SATB2

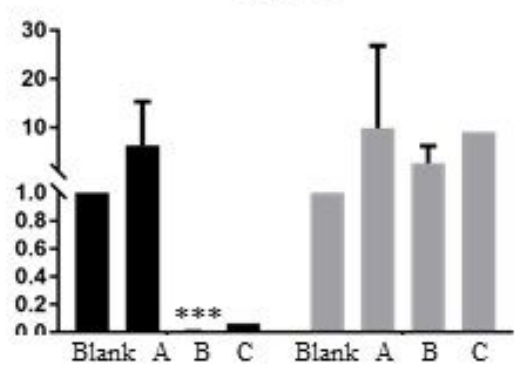

PKC

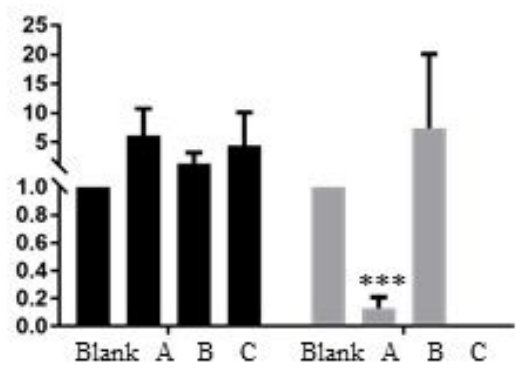

ITGA5

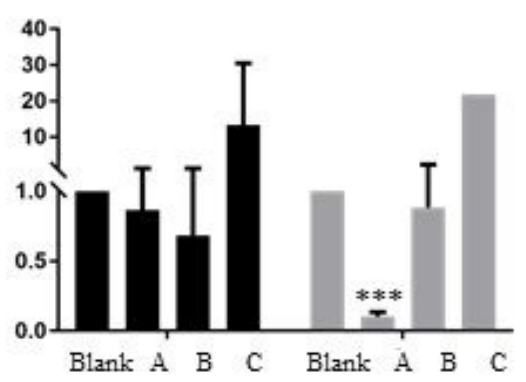

Ubc13
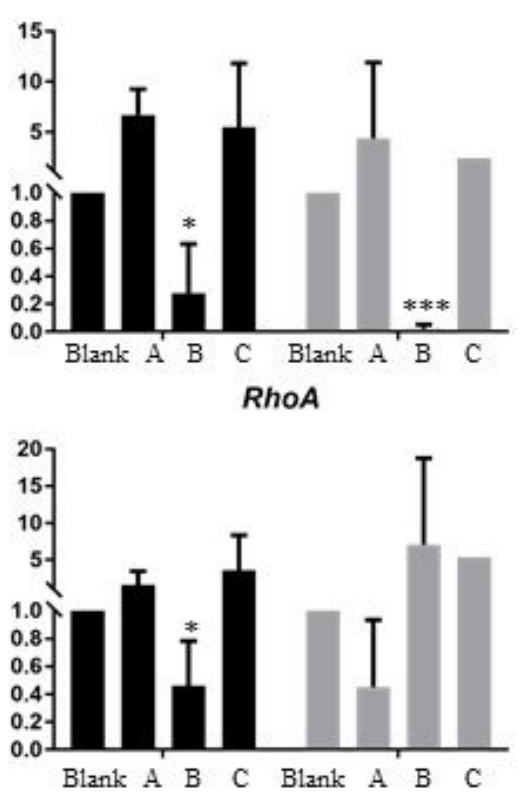

$R D X$

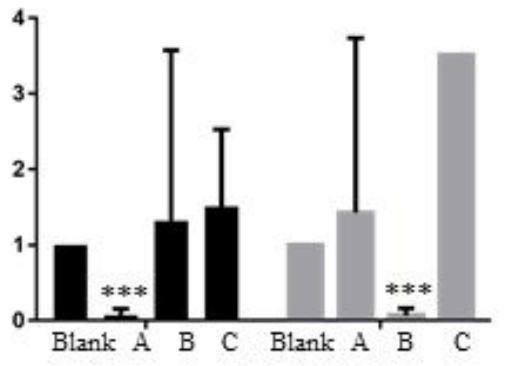

Ga13

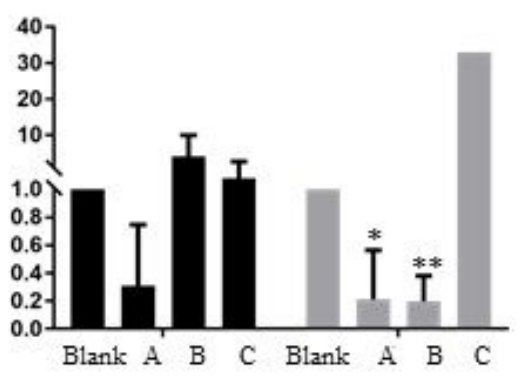

\section{Figure 7}

Effect of combination medication treatment on miR-31 target gene expression The effect of cisplatin (DDP) combined with GBK on the expression level of miR-31 target genes was detected by RT-qPCR assay. Three experimental groups were established, including $1 \mu \mathrm{g} / \mathrm{ml}$ DDP was added to group $A, 1$ $\mu \mathrm{g} / \mathrm{ml} \mathrm{DDP}$ and $1 \mu \mathrm{g} / \mathrm{ml} \mathrm{GBK}$ were added to group B, and $1 \mu \mathrm{g} / \mathrm{ml}$ DDP and $5 \mu \mathrm{g} / \mathrm{ml} \mathrm{GBK}$ were added to group C. ddH2O was added to the control group (Blank). Black bars indicate SUM-159 cells and gray bars 
indicate MCF-7 cells. Data are presented as mean \pm s.e.m. of three independent experiments. Student's t test, $* p<0.01, * \star p<0.001, * \star \star p<0.0001$.
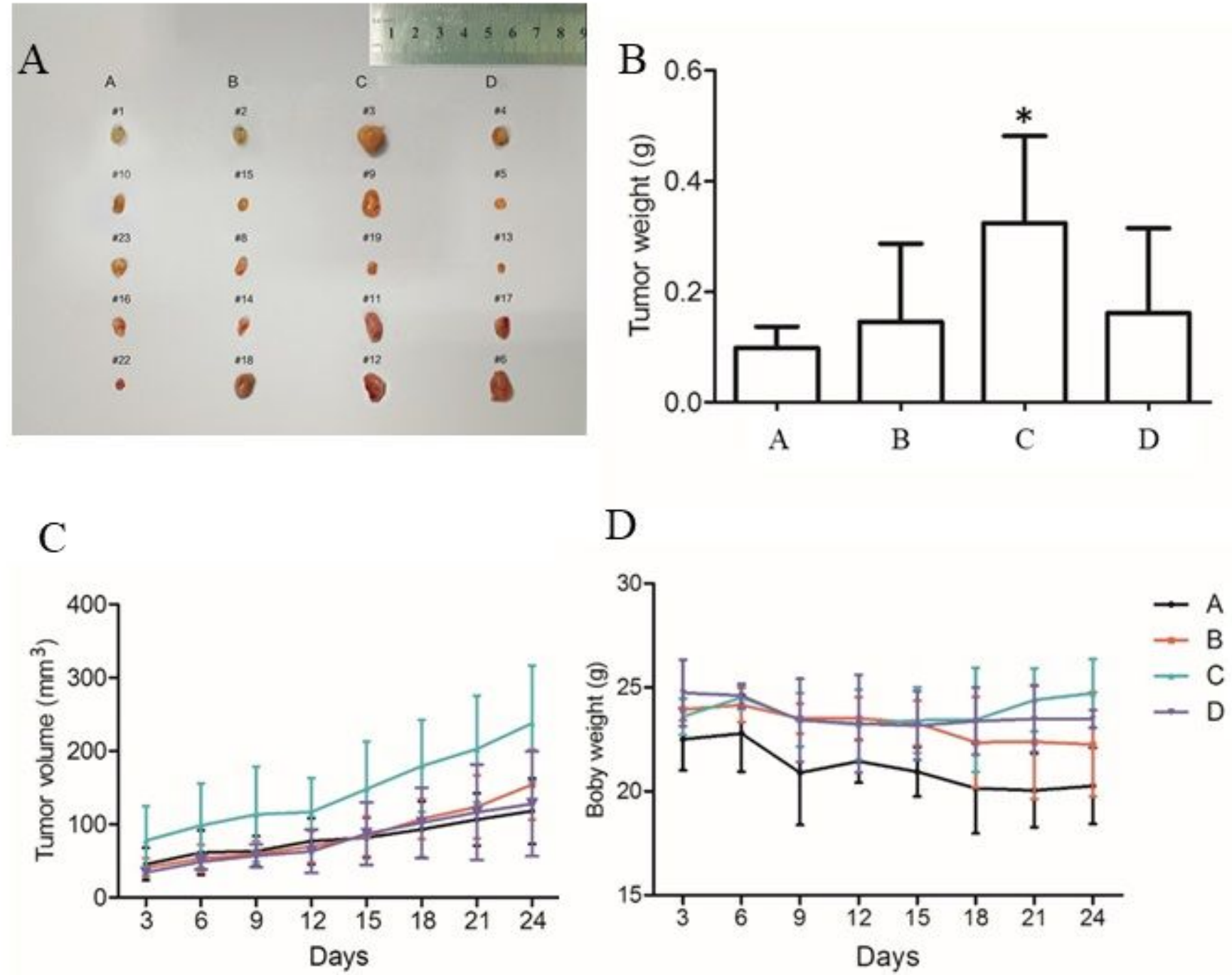

\section{Figure 8}

The anti-tumor effect of combination medication treatment on NOD/SCID mice bearing SUM-159 cells.

(A) SUM-159 cells were injected into flanks of NOD/SCID mice, and when tumors had grown to $~ 5-6 \mathrm{~mm}$ in diameter, GBK $10 \mathrm{mg} /(\mathrm{kg} .1 \mathrm{D})$ and DDP $1 \mathrm{mg} /(\mathrm{kg} .2 \mathrm{Ds})$ in Group A, GBK $5 \mathrm{mg} /(\mathrm{kg} .1 \mathrm{D})$ and DDP 1 $\mathrm{mg} /(\mathrm{kg} .2 \mathrm{Ds})$ in Group B, $0.9 \%$ saline in group C, and DDP $1 \mathrm{mg} /(\mathrm{kg} .2 \mathrm{Ds})$ in Group D was administered intraperitoneally as described for 24 days. (B) On day 24 , tumors were excised and subjected to weight analysis. (C) On day 0 , the tumor size was normalized to 1 for all the groups. Tumor volume was monitored and measured once every 3 days. (D) Body weight of the NOD/SCID mice in group A, B, C and $D$ were monitored for 24 days. Data are presented as mean \pm s.e.m. of five independent mice. Student's $t$

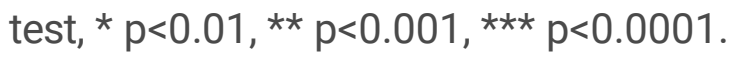




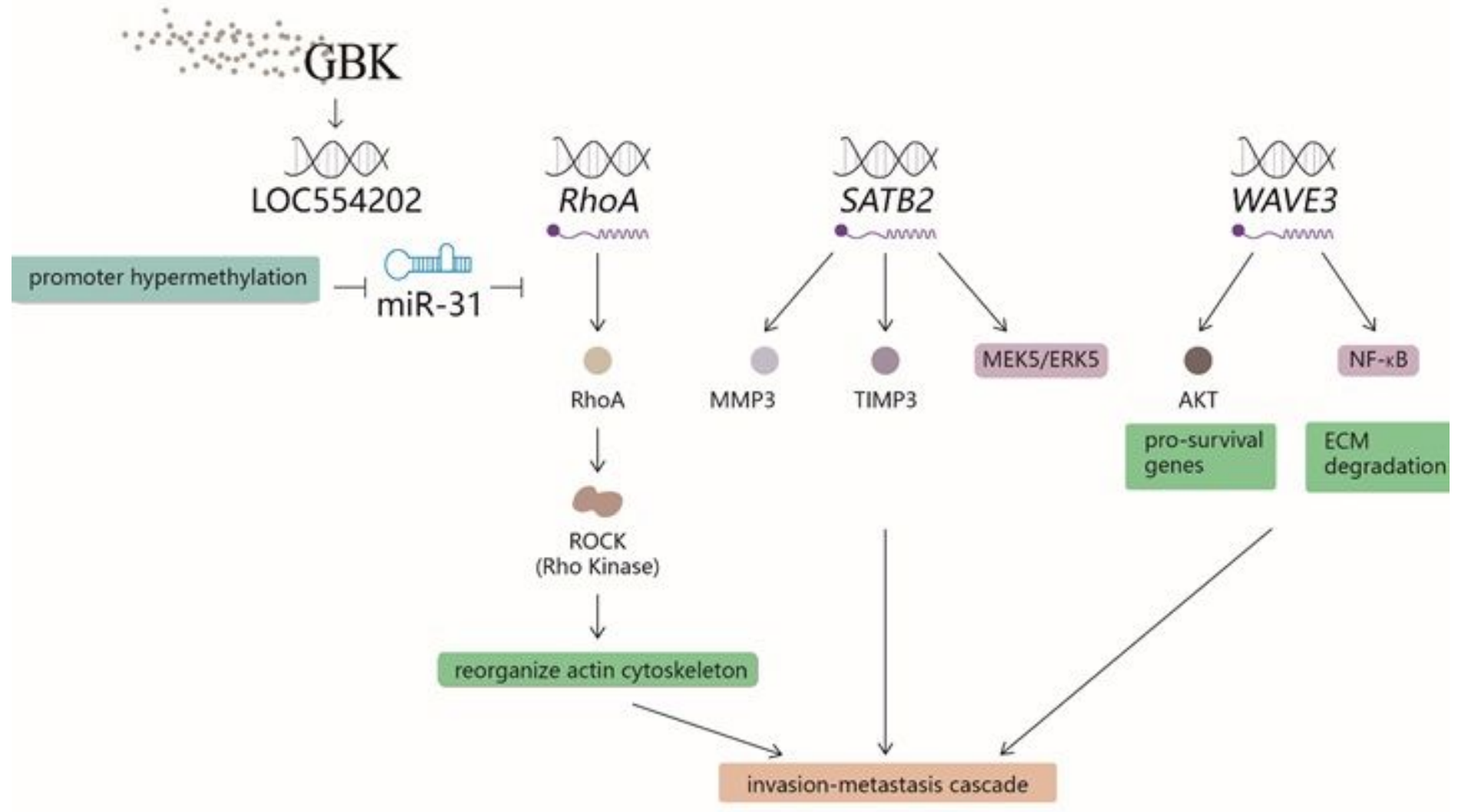

\section{Figure 9}

A proposed signaling network for GBK in inhibiting the migration and invasion of breast cancer cells. GBK treatment affects the epigenetic modification at $\mathrm{CpG}$ sites by downregulating DNA methyltransferases, thus the methylation levels at CpG of IncRNA LOC554202 decreased significantly under GBK treatment in a dose-dependent manner in breast cancer cell lines, which plays an important role in upregulating of both LOC554202 and miR-31 genes. MiR-31 directly acts on the 3'UTR region of multiple target genes like RhoA, SATB2 or WAVE3 which closely related to cancer cell invasion, migration and proliferation. GBK treatment impairs the expression of RhoA, SATB2 and WAVE3, whether the target proteins and signal pathways regulated by these three genes are also affected by GBK need to be further studied.

\section{Supplementary Files}

This is a list of supplementary files associated with this preprint. Click to download.

- SupplementalMaterials20210128.docx

- fulllengthgelsandblots.pdf 